\title{
Effect of different levels of weight loss on clinical outcomes in obese women with polycystic ovary syndrome underwent assisted reproduction
}

Yu-mei Li ( $\boldsymbol{\nabla}$ liyumei@csu.edu.cn )

Xiangya Hospital Central South University

Shimin Hu

Central South University Xiangya School of Public Health

Fangfang He

Xiangya Hospital Central South University

Donge Liu

Xiangya Hospital Central South University

\section{Research}

Keywords: body mass index; polycystic ovary syndrome; obese; assisted reproductive technology; weight loss

Posted Date: February 20th, 2020

DOI: https://doi.org/10.21203/rs.2.24111/v1

License: (c) (i) This work is licensed under a Creative Commons Attribution 4.0 International License. Read Full License 


\section{Abstract}

Background PCOS patient with a body mass index $(\mathrm{BMI})>30 \mathrm{~kg} / \mathrm{m} 2$ have been withhold fertility treatment in the absence of weight loss by the National Health Service,there is a lack of appropriately powered studies to explore the relationships between weight loss level and the clinical improvement in obese PCOS women undergoing ART. Objective To evaluate the effect of weight loss levels on clinical outcomes in obese women with polycystic ovary syndrome (PCOS) scheduled for assisted reproduction. Methods We conducted a non-randomized controlled clinical trial on 471 patients to compare the live birth rate and clinical pregnancy rate of the two groups. 395 patients received weight loss interventions before assisted reproduction (intervention group), 76 patients underwent assisted reproduction directly (nonintervention group). Results Compared to nonintervention group, the body mass index (BMI) was significantly lower $(27.30 \pm 2.63$ vs. $30.13 \pm 2.45, p=0.013)$ before embryo transfer, the rate of clinical pregnancy and live birth were significantly higher $(46.6 \%$ vs. $34.2 \%, p=0.047 ; 43.4 \%$ vs. $27.6 \%, p=0.017)$ in intervention group; Compared to patients with weight loss $\geq 15 \%$, live birth rate (OR=1.312, 95\% Cl: 0.699, $2.461, \mathrm{p}=0.398)$ and clinical pregnancy rate $(\mathrm{OR}=1.77,95 \% \mathrm{Cl}: 0.622,2.229, \mathrm{p}=0.617)$ were not significantly increased in women with weight loss in the range of $(\geq 10 \%,<15 \%)$; but were significantly lower in patients with weight loss $<10 \%$. Miscarriage rates were not significantly different among patients with every weight loss level. Conclusion Preconception weight loss could benefit the clinical outcomes, a target goal of $\geq 10 \%$ weight loss may recommend for obese women with PCOS before assisted reproduction.

\section{Background}

Polycystic ovary syndrome (PCOS) is one of the most common endocrine disorders, affecting about 4$6 \%$ of women in their reproductive age, and accounting for women with anovulatory infertility[1,2]. Women with PCOS have a 2.8-fold increased prevalence (50-80\%) of obesity compared with women without the syndrome[3, 4]. More than one third of Chinese PCOS women undergoing assisted reproductive technologies (ART) are overweight / obese[5].

Obese women who conceived with ART have lower pregnancy rates and higher miscarriage rates[6, 7]. PCOS patient with a body mass index $(\mathrm{BMI})>30 \mathrm{~kg} / \mathrm{m}^{2}$ have been withhold fertility treatment in the absence of weight loss by the National Health Service[8]. Obese PCOS women are always counseled to weight loss preconception, since as little as $5 \%$ of weight reduction can bring back regular menses and improve ovulation-inducing response and fertility medications[9]. Recent Obesity Guidelines have demonstrate that patients need not to normalize their weight or to achieve major weight loss to obtain health benefits, a medically supervised weight loss of 5\%-10\% was recommended[10]. How much weight loss should be recommended to obese PCOS women prior to ART? there is a lack of appropriately powered studies to explore the relationships between weight loss level and the clinical improvement in obese PCOS women undergoing ART. The aim of the study was to examine the link between different weight loss levels and clinical outcomes of obese PCOS patients underwent ART, and to attempt to recommend a target goal for weight loss. 


\section{Materials And Methods}

\section{Study design and patients}

A non-randomized controlled clinical trial was conducted at the Department of Assisted Reproductive of Xiangya Hospital affiliated Central South University. 471 obese PCOS women underwent their first in-vitro fertilization (IVF) cycles from January 2015 to December 2017 were recruited. Among them, 395 patients received weight loss interventions before IVF(intervention group), while other 76 patients underwent IVF directly (control group). Inclusion criteria were as follows: (1) PCOS women aged under 40 years and BMI $\geq 28 \mathrm{~kg} / \mathrm{m}^{2}$ [11]. (2) All patients met the indications for ART treatment. Patients with a history of diabetes mellitus, hypertension, hypothyroidism or hyperthyroidism were excluded in this study.

The study was approved by the Institutional Review Board of Xiangya Hospital. All patients agreed with the data utilization and gave informed consent before this investigation.

\section{Definition of overweight and obese and PCOS}

Patients' height and weight were measured by a professional medical assistant. BMI was calculated as weight / height ${ }^{2}\left(\mathrm{~kg} / \mathrm{m}^{2}\right)$. Based on the 2002 recommendation of the Bureau of Disease Control, Chinese Ministry of Health, BMI $\geq 28 \mathrm{~kg} / \mathrm{m}^{2}$ was defined as obesity, $24 \mathrm{~kg} / \mathrm{m}^{2} \leq \mathrm{BMI}<28 \mathrm{~kg} / \mathrm{m}^{2}$ was defined as overweight, $18 \mathrm{~kg} / \mathrm{m}^{2} \leq \mathrm{BMI}<24 \mathrm{~kg} / \mathrm{m}^{2}$ was defined as normal weight[12,13], PCOS was diagnosed according to the Rotterdam criteria in 2003[14].

\section{Weight loss intervention}

Studies has suggested that a low-carbohydrate diet have favorable weight loss and metabolic effects for obese women[15, 16]. so in this study, a high-protein and low-glycemic index diet was provided for weight loss. 12 weeks of dietary management were designed individually and supervised by a dietician. The management was consist of 8 weeks of weight-loss phase and 4 weeks of weight-maintenance phase, during the weight-loss phase, total caloric intake was 1000-1200 kcal per day. The balanced diet contained $40-45 \%$ proteins, $30-35 \%$ fat, $20-25 \%$ carbohydrates. In the maintenance phase, caloric intake was not limited and the balanced diet contained $25-30 \%$ proteins, $30 \%$ fat and $40-45 \%$ carbohydrates. After three months of intervention, patient underwent a health examination to determine the weight, and then underwent IVF.

\section{Clinical and laboratory protocols}

Standard luteal phase long protocol was used for ovarian stimulation, $0.1 \mathrm{mg} / \mathrm{d}$ triptorelin (Ferring AG) was administrated for 14-16 days on the 21 days of premenstrual cycle, then transvaginal ultrasonography and serum levels of follicle- stimulating hormone (FSH), luteinizing hormone (LH) and estradiol $\left(E_{2}\right)$ were measured to evaluate pituitary down-regulation, gonadotropin were administrated as ovary stimulation, the dose and frequency of monitoring was dependent on the ovarian response. 10000 
IU of human chorionic gonadotropin (hCG) was used for final oocytes maturation when two or three lead follicles exceeded $18 \mathrm{~mm}$, oocytes retrieved were conducted 34-36 hours later. IVF/ICSI procedures were based on our laboratory routines. No more than two cleaving stage embryos were transferred, progesterone by vaginal was used as luteal-phase support from the day of oocyte retrieved.

\section{Outcome measures and definitions}

Primary outcomes were clinical pregnancy rate and live birth rate per embryo transfer, the miscarriage rate was included as well. Live birth was defined as at least one alive child borned with the gestational age above 28 weeks, clinical pregnancy was documented by sonographic evidence of fetal cardiac activity, the loss of a clinical pregnancy prior to 28 weeks' gestational age was diagnosed as miscarriage.

\section{Statistical analysis}

The general clinical features and assisted reproductive outcomes between intervention group and nonintervention group were compared with the t-test for continuous variables or the chi-square test for categorical variables. According to the weight loss percentage (weight loss / initial weight), we divided the intervention group into four subgroups $(<5 \%, \geq 5 \%<10 \%, \geq 10 \%<15 \%, \geq 15 \%)$. The general clinical features between these subgroups were compared with the one-way analysis of variance for continuous variables or the chi-square test for categorical variables. Logistic regression analysis were used to estimate the relationship between weight loss levels and the assisted reproductive outcomes, adjusted for age, infertility category, number of embryos transfer, number of good quality embryos transfer and endometrial thickness on the trigger day. We set the weight loss levels $(<5 \%, \geq 5 \%<10 \%$, $\geq$ $10 \%<15 \%, \geq 15 \%$ ) as a categorical variable and set the highest weight loss percentage subgroup as the reference group. All analyses were performed using SPSS version 18.0 (SPSS Inc., Chicago, IL, USA). a was set to 0.05 .

\section{Results}

First, we compared the characteristics and clinical outcomes of the intervention group and nonintervention group (Table 1). The distribution of infertility category, mean BMI before weight loss were similar between the two groups, intervention group had lower BMI before embryo transfer $(p=0.013)$, thicker endometrial thickness on day of transfer $(p=0.007)$, higher clinical pregnancy $(p=0.047)$, as well as higher live birth rate $(p=0.017)$.

Second, 395 obese patients who received the weight loss intervention were divided into four groups according to the weight loss level $(<5 \%, \geq 5 \%<10 \%, \geq 10 \%<15 \%, \geq 15 \%)$, the clinical outcomes were analyzed. 91 (23\%) subjects experienced weight loss $<5 \%$; $133(33.7 \%)$ subjects achieved weight loss between $\geq 5 \%$ and $<10 \% ; 92$ (23.3\%) of these subjects successfully achieved weight loss between $\geq 10 \%$ and $15 \%$, and $79(20 \%)$ subjects lost weight $\geq 15 \%$ of initial weight. Baseline comparisons among the four weight loss levels groups revealed no significant differences in the ages, mean BMI before weight 
loss, mean number of embryos and good quality embryos transferred, endometrial thickness on day of transfer (Table 2).

After adjusted for age, number of embryos and good quality embryos transferred, endometrial thickness, compared with patients with weight loss $\geq 15 \%$ of initial weight (clinical pregnancy rate: $60.8 \%$, live birth rate: $54.4 \%$ ), the live birth rate and clinical pregnancy rate were similar in those women with weight loss between $10 \%$ and $15 \%$ (clinical pregnancy rate: $60.9 \%$, live birth rate: $57.6 \%$ ); however, the clinical pregnancy rate and live birth rate were significantly lower in the patients with weight loss $<10 \%(<5 \%$ : clinical pregnancy rate: $29.7 \%, \mathrm{OR}=0.278, p<0.001$, live birth rate: $26.4 \%, \mathrm{OR}=0.305, p<0.001 ; \geq 5 \%<10 \%$ : clinical pregnancy rate: $39.8 \%, \mathrm{OR}=0.455, p=0.009$, live birth rate: $35.3 \%, \mathrm{OR}=0.305, p=0.014)$. No significant differences in miscarriage rate were found among patients with every weight loss level(Table 3).

\section{Discussion}

The present study showed pretreatment weight loss resulted in a significant improvement in clinical pregnancy rate and live birth rate for obese PCOS women scheduled for ART. Further, $\geq 10 \%$ of weight loss could significantly improve the rates of clinical pregnancy and live birth compared to patients with weight loss $<10 \%$. Nevertheless, the clinical pregnancy and live birth rates were nearly identical between patients with weight loss $\geq 10 \%(10 \%-15 \%)$ and $\geq 15 \%$.

Numerous studies have focused on short-term weight reduction interventions and fertility outcomes for obese women underwent fertility treatment. An Australian study showed that patients experienced an intensive 12-week lifestyle intervention had an average of $6.6 \mathrm{~kg}$ weight reduction, and a significantly improvement in live birth rate was noticed after weight reduction[17]. And a systematic review published in 2014 found that weight loss prior to IVF/ICSI was associated with increased chances of pregnancy and live birth among obese infertile women[18]. In accordance with these findings, our studies showed that after 12 weeks of dietary management intervention, a substantial weight loss was obtained, and the live birth rate was significantly improved. However, a recent study suggests that intensive weight loss did not affect live birth rates in obese women scheduled for IVF[19]. The reason maybe that the eligibility criteria and the final average weight loss level were different. More powerful studies are needed to guide clinicians and to make patients reach targeted health outcomes goals.

There is evidence that a $2 \%-5 \%$ of minimal weight loss can improve ovulatory function and spontaneous pregnancy, $5 \%-10 \%$ of total weight reduction can improve pregnancy outcomes from ovulatory cycles[20, 21]. In this study, we found that obese women with $\geq 10 \%$ of weight reduction could significantly improve the clinical pregnancy rate and live birth rate, further increased weight loss amounts provided the same benefits. So for obese women with PCOS scheduled to IVF/ICSI, an initial goal of $10 \%$ weight loss may be recommended prior to IVF/ICSI, which provides significantly implications for current practice. Future prospectively designed studies are needed to generate level I evidence for the practice. 
The miscarriage rates were not significantly different between intervention group and nonintervention group, in addition, there was no obvious effect of weight loss degrees on miscarriage rate in the present study, so weight loss could not completely explain the improvement in live birth rates. The mechanism(s) of weight loss for improved clinical outcomes for PCOS patients underwent IVF/ICSI treatment remain speculative, further studies are needed to clarify the mechanisms by which weight loss improve the clinical outcomes.

The present study has several limitations. First, because of the age limit, the selection bias cannot be ruled out. Second, before and after weight loss intervention, only BMI was evaluated, the ratio of reduced fat and muscle is not clear, although as an easily and simply method, BMI is widely used in clinical to evaluate the effect of weight reduction, more possible specific evaluation index should be explored in further studies. Finally, it cannot be excluded that, other than BMI and weight loss, one or more confounding factors were responsible for the differences in the outcome.

\section{Conclusion}

The study showed that preconception weight loss could benefit the clinical outcomes in obese PCOS women scheduled for IVF, and $\geq 10 \%$ of weight loss may be recommend for obese PCOS women as a target goal before IVF.

\section{Abbreviations}

PCOS\polycystic ovary syndrome; BMI: body mass index; ART: assisted reproductive technologies; IVF: invitro fertilization; FSH: follicle- stimulating hormone; LH: luteinizing hormone; E2: estradiol; hCG: human chorionic gonadotropin;ICSI:intracytoplasmic sperm injection.

\section{Declarations}

\section{Acknowledgments}

We would like to thank all the participants and co-workers in this study. There has been no financial support.

\section{Funding}

None.

\section{Availability of data and material}

The data sets used and/or analyzed during the current study are available from the corresponding author on reasonable request.

\section{Authors' contributions}


YML were the chief investigators who completed the entire study, including procedures, conception, design and completion. FFH were responsible for the collection of data. YML and SMH analysed the data and drafted the manuscript together. DEL supervised the study. All authors participated in the ultimate interpretation of the study data and manuscript revisions. All authors read and approved the final manuscript.

\section{Ethics approval and consent to participate}

The study was approved by the Institutional Review Board of Xiangya Hospital. All patients agreed with the data utilization and gave informed consent before this investigation.

\section{Consent for publication}

NA.

\section{Competing interests}

The authors declare that they have no competing interests.

\section{Author details}

Yumei Li, Department of Assisted Reproduction, Xiangya Hospital affiliated Central South University, Changsha, 414000, People's Republic of China.

E-mail: liyumei@csu.edu.cn

\section{References}

1. Norman RJ, Dewailly D, Legro RS, Hickey TE. Polycystic ovary syndrome. The Lancet. 2007;370(9588):685-97.

2. Li R, Zhang Q, Yang D, Li S, Lu S, Wu X, et al. Prevalence of polycystic ovary syndrome in women in China: a large community-based study. Hum Reprod. 2013;28(9):2562-9.

3. Lim SS, Davies MJ, Norman RJ, Moran LJ. Overweight, obesity and central obesity in women with polycystic ovary syndrome: a systematic review and meta-analysis. Hum Reprod Update. 2012;18(6):618-37.

4. Dumesic DA, Oberfield SE, Stener-Victorin E, Marshall JC, Laven JS, Legro RS. Scientific Statement on the Diagnostic Criteria, Epidemiology, Pathophysiology, and Molecular Genetics of Polycystic Ovary Syndrome. Endocr Rev. 2015;36(5):487-525.

5. Sheng Y, Lu G, Liu J, Liang X, Ma Y, Zhang X, et al. Effect of body mass index on the outcomes of controlled ovarian hyperstimulation in Chinese women with polycystic ovary syndrome: a multicenter, prospective, observational study. J Assist Reprod Genet. 2017;34(1):61-70. 
6. Metwally M, Ong KJ, Ledger WL, Li TC. Does high body mass index increase the risk of miscarriage after spontaneous and assisted conception? A meta-analysis of the evidence. Fertil Steril. 2008;90(3):714-26.

7. Bellver J. Obesity and the risk of spontaneous abortion after oocyte donation. Fertility and Sterility. 2003;79(5):1136-40.

8. Teede HJ, Joham AE, Paul E, Moran LJ, Loxton D, Jolley D, et al. Longitudinal weight gain in women identified with polycystic ovary syndrome: results of an observational study in young women. Obesity (Silver Spring). 2013;21(8):1526-32.

9. Goodman NF, Cobin RH, Futterweit W, Glueck JS, Legro RS, Carmina E, et al. American Association of Clinical Endocrinologists, American College of Endocrinology, and Androgen Excess and Pcos Society Disease State Clinical Review: Guide to the Best Practices in the Evaluation and Treatment of Polycystic Ovary Syndrome - Part 2. Endocr Pract. 2015;21(12):1415-26.

10. Ryan D, Heaner M. Guidelines (2013) for managing overweight and obesity in adults. Preface to the full report. Obesity (Silver Spring). 2014;22:S40-S.

11. MoHDC B. Chinese adult overweight and obese prevention and control guideline (on trial). 2002.

12. He W, Li Q, Yang M, Jiao J, Ma X, Zhou Y, et al. Lower BMl cutoffs to define overweight and obesity in China. Obesity (Silver Spring). 2015;23(3):684-91.

13. Oakkar EE, Stevens J, Truesdale KP, Cai J. BMI and all-cause mortality among Chinese and Caucasians: the People's Republic of China and the Atherosclerosis Risk in Communities Studies. Asia Pac J Clin Nutr. 2015;24(3):472-9.

14. Rotterdam EA-SPcwg. Revised 2003 consensus on diagnostic criteria and long-term health risks related to polycystic ovary syndrome (PCOS). Hum Reprod. 2004;19(1):41-7.

15. Nordmann AJ, Nordmann A, Briel M, Keller U, Yancy WS, Brehm BJ, et al. Effects of low-carbohydrate vs low-fat diets on weight loss and cardiovascular risk factors: a meta-analysis of randomized controlled trials. Arch Intern Med. 2006;166:285-93.

16. Gardner CD, Kiazand A, Alhassan S, Kim S, Stafford RS, Balise RR, et al. Comparison of the Atkins, Zone, Ornish, and LEARN diets for change in weight and related risk factors among overweight premenopausal women: the A TO Z Weight Loss Study: a randomized trial. JAMA. 2007;297(9):96977.

17. Sim KA, Dezarnaulds GM, Denyer GS, Skilton MR, Caterson ID. Weight loss improves reproductive outcomes in obese women undergoing fertility treatment: a randomized controlled trial. Clin Obes. 2014;4(2):61-8.

18. Sim KA, Partridge SR, Sainsbury A. Does weight loss in overweight or obese women improve fertility treatment outcomes? A systematic review. Obes Rev. 2014;15(10):839-50.

19. Einarsson S, Bergh C, Friberg B, Pinborg A, Klajnbard A, Karlstrom PO, et al. Weight reduction intervention for obese infertile women prior to IVF: a randomized controlled trial. Hum Reprod. 2017;32(8):1621-30. 
20. Kiddy DS, Hamilton-Fairley D, Bush A, Short F, Anyaoku V, Reed MJ, et al. Improvement in endocrine and ovarian function during dietary treatment of obese women with polycystic ovary syndrome. Clin Endocrinol (Oxf). 1992;36(1):105-11.

21. Crosignani PG, Colombo M, Vegetti W, Somigliana E, Gessati A, Ragni G. Overweight and obese anovulatory patients with polycystic ovaries: parallel improvements in anthropometric indices, ovarian physiology and fertility rate induced by diet. Hum Reprod. 2003;18(9):1928-32.

\section{Tables}

\section{TABLE 1}

Characteristics and clinical outcomes of the obese patients with PCOS (BMI $\geqq 28$ ) between two groups 


\begin{tabular}{|c|c|c|c|c|}
\hline Variable & $\begin{array}{l}\text { intervention } \\
\text { group }\end{array}$ & $\begin{array}{c}\text { nonintervention } \\
\text { group }\end{array}$ & $\mathrm{t}$ & $\begin{array}{c}\mathrm{P} \\
\text { value }\end{array}$ \\
\hline Numbers & 395 & 76 & & \\
\hline Mean ages (years) & $30.67 \pm 5.33$ & $29.32 \pm 4.05$ & -2.520 & 0.013 \\
\hline \multicolumn{5}{|l|}{ Infertility category } \\
\hline No. of primary infertility (\%) & $166(42.0)$ & $37(48.7)$ & 1.152 & 0.283 \\
\hline No. of secondary infertility (\%) & $229(58.0)$ & $39(51.3)$ & & \\
\hline Mean BMI before weight loss & $30.28 \pm 2.25$ & $30.13 \pm 2.45$ & -0.531 & 0.596 \\
\hline $\begin{array}{l}\text { Mean BMI before embryo } \\
\text { transfer }\end{array}$ & $27.30 \pm 2.63$ & $30.13 \pm 2.45$ & -2.520 & 0.013 \\
\hline No. of transferred embryos & $1.93 \pm 0.22$ & $1.956 \pm 0.20$ & 0.413 & 0.680 \\
\hline $\begin{array}{l}\text { No. of good quality transferred } \\
\text { embryos }\end{array}$ & $1.74 \pm 0.64$ & $1.71 \pm 0.69$ & -0.322 & 0.748 \\
\hline $\begin{array}{l}\text { Endometrial thickness on day of } \\
\text { transfer }\end{array}$ & $10.74 \pm 1.96$ & $10.05 \pm 2.27$ & -2.716 & 0.007 \\
\hline Clinical pregnancy rate\% (n) & $46.6(184)$ & $34.2(26)$ & 3.949 & 0.047 \\
\hline Miscarriage rate (\%) & $3.75(14)$ & $6.6 \quad(5)$ & 1.516 & 0.218 \\
\hline Live birth rate (\%) & $43.4(167)$ & $27.6(21)$ & 5.701 & 0.017 \\
\hline
\end{tabular}

\section{TABLE 2}

Baseline characteristics of the obese patients in intervention group 


\begin{tabular}{|c|c|c|c|c|c|c|}
\hline \multirow[t]{2}{*}{ Variable } & \multicolumn{4}{|c|}{ weight loss level } & \multirow[t]{2}{*}{$\mathrm{F}$} & \multirow{2}{*}{$\begin{array}{c}\mathrm{P} \\
\text { value }\end{array}$} \\
\hline & $<5 \%$ & $\begin{array}{c}\geq 5 \%< \\
10 \%\end{array}$ & $\begin{array}{c}\geq 10 \%< \\
15 \%\end{array}$ & $\geq 15 \%$ & & \\
\hline numbers & $91(23.0)$ & $\begin{array}{c}133 \\
(33.7)\end{array}$ & $92(23.3)$ & $79(20.0)$ & & \\
\hline mean ages & $\begin{array}{c}30.40 \pm \\
5.86\end{array}$ & $\begin{array}{c}30.72 \pm \\
5.38\end{array}$ & $\begin{array}{c}31.74 \pm \\
5.10\end{array}$ & $\begin{array}{c}29.65 \pm \\
4.67\end{array}$ & 2.302 & 0.077 \\
\hline Infertility category & & & & & & \\
\hline Primary infertility & $39(42.9)$ & $47(35.3)$ & $33(35.9)$ & $47(59.5)$ & 13.792 & 0.003 \\
\hline secondary infertility & $52(57.1)$ & $86(64.7)$ & $59(64.1)$ & $32(40.5)$ & & \\
\hline mean BMI before weight loss & $\begin{array}{c}30.35 \pm \\
2.30\end{array}$ & $\begin{array}{c}30.07 \pm \\
2.37\end{array}$ & $\begin{array}{c}30.11 \pm \\
2.06\end{array}$ & $\begin{array}{c}30.75 \pm \\
2.14\end{array}$ & 1.739 & 0.158 \\
\hline $\begin{array}{l}\text { mean BMI on transferred } \\
\text { day }\end{array}$ & $\begin{array}{c}29.46 \pm \\
2.24\end{array}$ & $\begin{array}{c}27.87 \pm \\
2.20\end{array}$ & $\begin{array}{c}26.39 \pm \\
1.86\end{array}$ & $\begin{array}{c}24.92 \pm \\
2.03\end{array}$ & 75.109 & $\begin{array}{c}< \\
0.001\end{array}$ \\
\hline No. of transferred embryos & $\begin{array}{c}1.96 \pm \\
0.19\end{array}$ & $\begin{array}{c}1.96 \pm \\
0.19\end{array}$ & $\begin{array}{c}1.91 \pm \\
0.28\end{array}$ & $\begin{array}{c}1.96 \pm \\
0.19\end{array}$ & 1.113 & 0.344 \\
\hline $\begin{array}{l}\text { No. of good quality } \\
\text { transferred embryos }\end{array}$ & $\begin{array}{c}1.74 \pm \\
0.65\end{array}$ & $\begin{array}{c}1.70 \pm \\
0.70\end{array}$ & $\begin{array}{l}1.79 \pm \\
0.55\end{array}$ & $\begin{array}{c}1.73 \pm \\
0.66\end{array}$ & 0.389 & 0.761 \\
\hline $\begin{array}{l}\text { Endometrial thickness on } \\
\text { day of transfer }\end{array}$ & $\begin{array}{c}10.63 \pm \\
1.94\end{array}$ & $\begin{array}{c}10.66 \pm \\
1.98\end{array}$ & $\begin{array}{c}10.70 \pm \\
1.79\end{array}$ & $\begin{array}{c}11.03 \pm \\
2.11\end{array}$ & 0.767 & 0.513 \\
\hline
\end{tabular}

\section{TABLE 3}

Clinical outcomes of the obese patients in intervention group 


$$
\begin{array}{llll}
<5 \%(\mathrm{n}=91) & \geq 5 \%<10 \% & \geq 10 \%<15 \% & \geq 15 \% \\
(\mathrm{n}=133) & (\mathrm{n}=92) & (\mathrm{n}=79)
\end{array}
$$

\begin{tabular}{lllll}
\hline clinical pregnancy & $29.7(27)$ & $39.8(53)$ & $60.9(56)$ & $60.8(48)$
\end{tabular}

rate $\%(n)$

OR (95\% CI )

$0.278(0.145$

$0.455(0.253$,

1.177 (0.622,

2.229)

$P$ value

$$
<0.001
$$

0.009

0.617

miscarriage rate $\%$

3.3(3)

$3.8(5)$

$1.1(1)$

$6.3(5)$

(n)

OR (95\% CI )

$\begin{array}{llll}0.487(0.110, & 0.580(0.156, & 0.172(0.019, & 1 \\ 2.152) & 2.165) & 1.559)\end{array}$

$\mathrm{P}$ value

0.343

0.418

0.117

Live birth rate \% (n) 26.4 (24)

$35.3(47)$

57.6 (53)

$54.4(43)$

OR (95\% CI )

$0.305(0.158$

$0.481(0.268$

1.312 (0.699,

1

0.588)

0.863)

2.461)

$P$ value

$<0.001$

0.014

0.398 